\title{
Evaluation of the Photovoltaic System Installation Impact to an Electric Power Grid. Part 2: Impact analysis of photovoltaic installation to an electric power grid by applying a nonlinear analysis model
}

\author{
(ㅅ)

\section{Juan Ernesto Wyss Porras} \\ BS in Civil Engineering, Masters degree in Economics and Business Administration at Universidad del Valle \\ de Guatemala. Masters degree in Environmental and Renewable Energy Systems and Doctoral Course \\ Student at Gifu University. Antigua Guatemala [Sacatepéquez] Guatemala. <s3815001@edu.gifu-u.ac.jp>. \\ Susumu Shimada \\ Ph.D degree at Kobe University. Research scientist at AIST in Japan: National Institute of Advanced \\ Industrial Science and Technology, Renewable Energy Research Center. Koriyama [Fukushima] Japan. \\ <susumu.shimada@aist.go.jp>

\section{Jun Yoshino} \\ Graduate School of Science at Kyoto University. Doctor of Science in Meteorology. Associate Professor, \\ Graduate School of Engineering, Gifu University. Gifu-shi [Gifu] Japan. <jyoshino@gifu-u-ac.jp>

\section{Tomonao Kobayashi} \\ Professor, Environmental and Renewable Energy Systems, Gifu University. Research field: Applied \\ Meteorology and Ocean Engineering. Especially the application of weather forecasting to renewable energy. \\ Gifu-shi [Gifu] Japan. <kobat@gifu-u.ac.jp>.

\begin{abstract}
The impact of the installation of a large-scale photovoltaic (PV) system to the electric power grid management is analyzed in a series of two works: Part 1 and Part 2. The PV generation is estimated in Part 1 (see Labor \& Engenho, v.9, n.1, p.90-102, 2015). By applying the results of Part 1, the Guatemala's electric power grid management is simulated with a virtually-installed large-scale PV system using a nonlinear analysis model in this work, Part 2. The thermal power plants reduced their operation in the simulation by installing the PV system, however the effect of the PV system installation to the plants is different in each thermal power plant. The contribution of the PV installation to the reduction of operation of the largest generation thermal plants is very limited or null, because of their high efficiency and low cost in operation. On the other hand, the middlelarge generation thermal power plants reduce their operation after installing PV system in this simulation. The reduction of thermal plants' operation becomes large, but its reduction gradient becomes small as the PV installing capacity becomes large.
\end{abstract}

\section{Keywords}

System Dynamics, sensitivity analysis, priority, efficiency, energy cost. 


\section{Introduction}

Photovoltaic (PV) energy has been expanding rapidly throughout the developed nations around the world. According to the "PV status report 2012" (Jäger-Waldau, 2012), from the European Commission, this expansion is due to the creation of new laws promoting its use. Emerging markets in The Americas have been also created similar laws, however PV development has not reached such levels.

In a series of two works: Part 1 and Part 2, Guatemala, which is located in the lower latitudes of Central America, is selected as the target for the analysis of photovoltaic (PV) installation. The solar irradiance and the PV output were evaluated in Part 1 (Wyss Porras et al., 2015). In this work, Part 2, the evaluated PV output from Part 1 is used to simulate the electric power grid management after installing PV system, and the impacts of the PV installation to the ordinal electric power grid are evaluated with a nonlinear analysis tool.

There are two main reasons for choosing Guatemala as a target country for the present work: There were no PV power plants connected to the electric power grid in December 2013. Therefore we can compare the simulated power grid management after installing a PV system with the current status, and can discuss the effect of the PV installation. Next, Guatemala's electric power grid consists in only one grid which connects all the urban areas and most of the rural areas, this makes an impact analysis of the PV installation easy.

There are several approaches to apply the nonlinear analysis tools to analyze the management of the photovoltaic energy. Movilla, Miguel and Blázquez (2013) use the tool named System Dynamics, in order to analyze the future profitability of photovoltaic energy in Spain. Hsu (2012), Ahmad, Mat Tahar, Muhammad-Sukki, Munir and Abdul Rahim (2015) and Silveira, Tuna and Lamas (2013) use the System Dynamics to analyze the role of policies in the development of photovoltaic energy in their respective countries. Their research is focused on the economic and political assessment of PV systems in the target countries. However, they do not discuss the integration of PV systems in to the electric power grid from the engineering point of view. Since PV output varies frequently due to the diurnal motion and weather changing, PV output varies evidently during the day, and the detailed analysis is required for the management of the electric power grid after PV installation.

Li, Zhou, Li and Zeng (2012) use the System Dynamics to analyze power grid engineering projects management. They found that System Dynamics can be used to optimize the management aspects of power grid engineering projects. Kaifel (2011) develops a model for the simulation and optimization of a power grid system including renewable energies, such as PVs and wind powers. Ramli, Hiendro, Sedraoui, and Twaha (2015) discuss the optimal sizing of grid-connected PV system in Saudi Arabia.

In this work, the System Dynamics is employed as an analysis tool to evaluate a future grid management with a large-scale PV system in Guatemala. From the analytical results the impact and potential of the PV installation are discussed.

\section{Guatemala's Energy Conditions}

\subsection{Location and topography of Guatemala}

The target country, Guatemala, is located at the low latitudes between $14^{\circ} \mathrm{N}$ to $18^{\circ} \mathrm{N}$ in Central America as shown in Figure 1.

The southern plains face the Pacific Ocean and have the mountains called Sierra Madre in the back. The large tract of flat land is in the north. The climate is subtropical, and it has wet season from June to November and dry season from December to the next May. 


\subsection{Electric Power Plants}

As of January 2012, there were 85 power plants in Guatemala, and their total capacity was 2,795 MW. Guatemala's energy demand is supplied by a combination of hydro, geothermal, biomass and thermal power plants. Table 1 indicates the number of the plants. Figures 2 and 3 show the installed capacity and energy produced in Guatemala in 2013, respectively.

Table 1. Summary of Guatemala's energy supply as of January 2012, (Administrador del Mercado Mayorista 2014).

\begin{tabular}{|l|c|c|c|}
\hline Energy Source & $\begin{array}{c}\text { Number of } \\
\text { power plants }\end{array}$ & $\begin{array}{c}\text { Total Installed } \\
\text { Capacity (MW) }\end{array}$ & Fuel Type \\
\hline Hydro Power & 27 & 880.0 & NA \\
\hline $\begin{array}{l}\text { Geothermal } \\
\text { Power }\end{array}$ & 2 & 49.2 & NA \\
\hline Biomass Power & 25 & 538.0 & $\begin{array}{l}\text { Sugarcane } \\
\text { bagasse } \\
\text { Diesel, } \\
\text { Thermal Power }\end{array}$ \\
\hline
\end{tabular}

It can be seen from these figures that the country relies heavily on the hydro and the thermal power plants. Their installations are about one third and 40 $\%$ respectively and their energy productions cover about half and one third.

Figure 4 shows the energy use ratio of the power plants in each month.

The output of the hydropower plants changes due to the precipitation, and it becomes large after the rainy season from June to November. This happens because most hydropower plants don't have yearly-regulated reservoirs, which allow to store water during the rainy season and to generate electric power during the whole dry season.

The biomass power plants use the waste material from the production of sugar from sugar cane as fuel. Their generation also changes evidently in a year due to the agricultural cycle of sugar cane as shown in Figure 4.

On the other hand, the output of geothermal power plants is constant throughout the year.

The thermal power plants are categorized into three types from the fuels: coal, heavy oil and gas. The energy price, efficiency and the reaction time are different among them. The specifications of major thermal power plants are listed in Table 2.

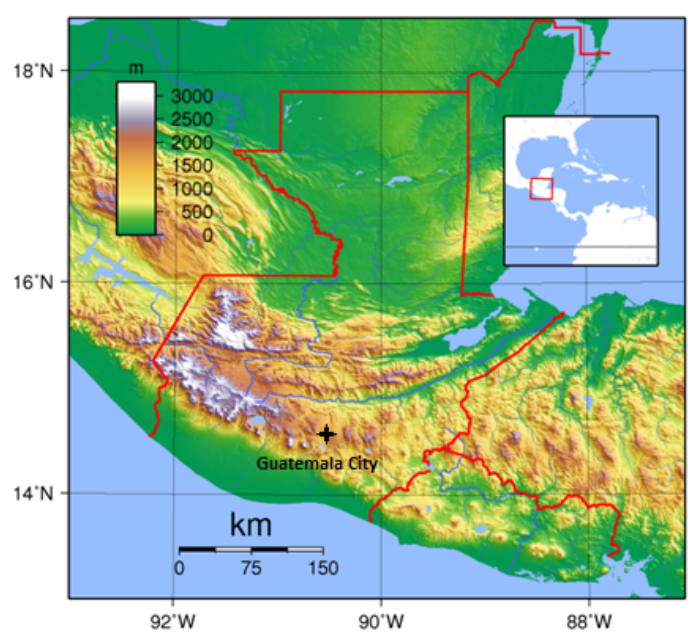

Figure 1. Guatemala's topography (Instituto Geográfico Nacional, Guatemala C.A. 2014).

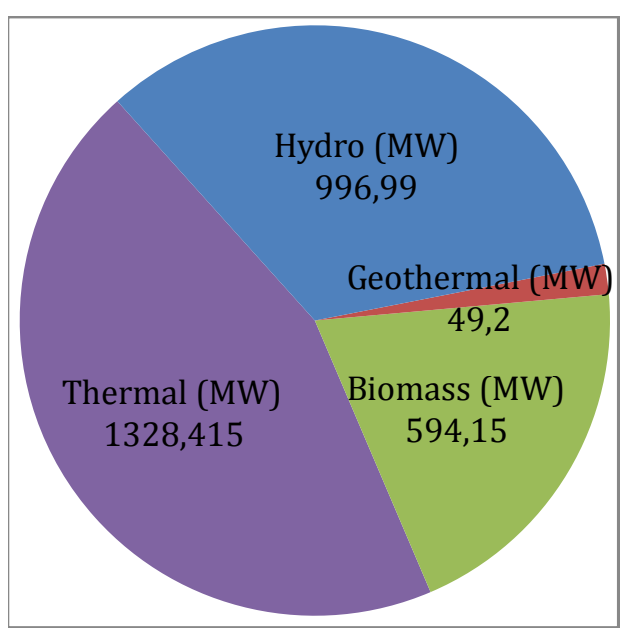

Figure 2. Guatemala's installed capacity, of electric power plants as of January 2013 (Administrador del Mercado Mayorista 2014).

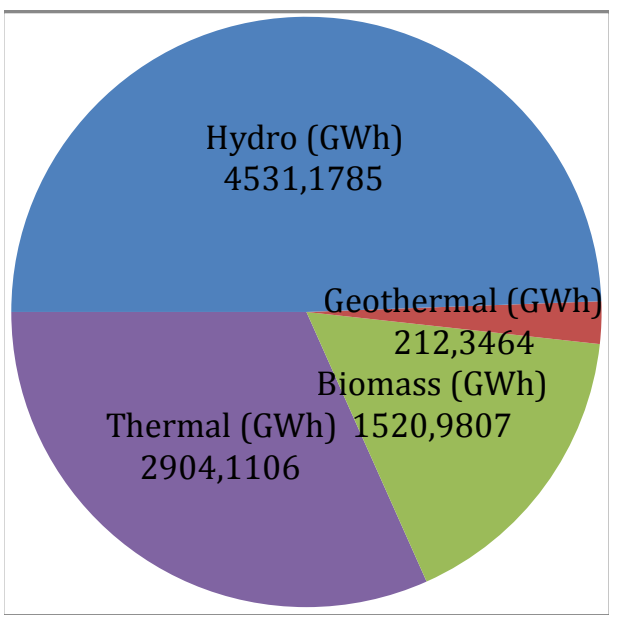

Figure 3. Guatemala's energy production in electric power plants for the year 2013 (Administrador del Mercado Mayorista 2014). 


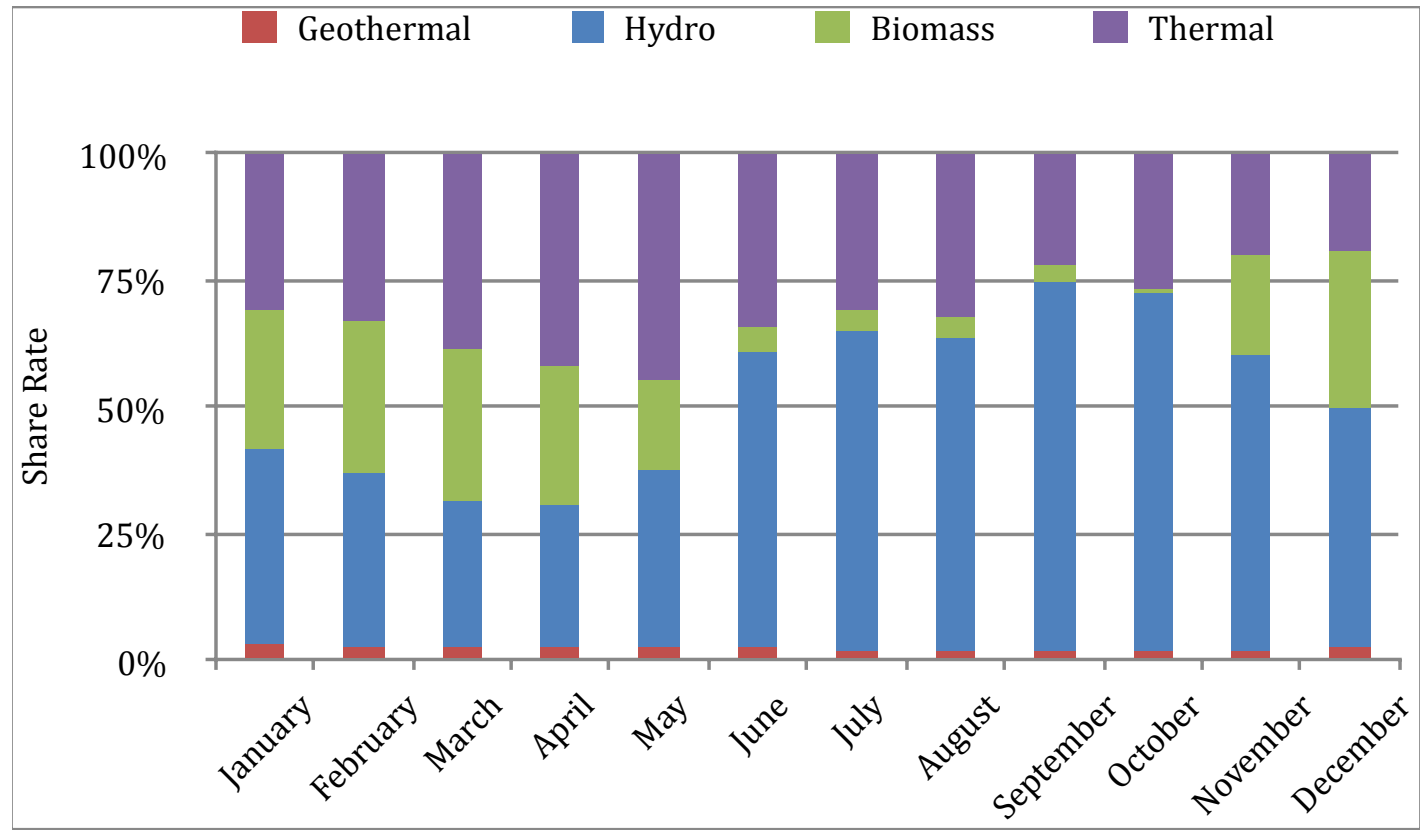

Figure 4. Monthly energy supply share in Guatemala in 2011 (Administrador del Mercado Mayorista 2014).

Table 2. Thermal power plants in Guatemala. Sorted with the actual power generation in the year 2011.

\begin{tabular}{|c|c|c|c|}
\hline Thermal Power Plants & $\begin{array}{l}\text { Installed Capacity } \\
\text { (MW) }\end{array}$ & Fuel Type & $\begin{array}{l}\text { Actual Generation in } \\
2011 \text { (MWh/year) }\end{array}$ \\
\hline San José & 139.00 & Coal & $822,155.12$ \\
\hline Arizona & 160.00 & Heavy Oil & $621,056.47$ \\
\hline Poliwatt & 129.36 & Heavy Oil & $558,486.51$ \\
\hline Las Palmas 2 & 83.00 & Coal & $437,521.09$ \\
\hline Genor & 46.24 & Heavy Oil & $203,001.98$ \\
\hline La Libertad & 20.00 & Coal & $100,874.54$ \\
\hline Puerto Quetzal Power & 118.00 & Heavy Oil & $94,380.42$ \\
\hline Las Palmas & 66.80 & Heavy Oil & $91,428.92$ \\
\hline Sidegua & 44.00 & Heavy Oil & $26,000.00$ \\
\hline Electro Generación & 15.75 & Heavy Oil & $21,287.98$ \\
\hline Industria Textiles del Lago (ITDL10) & 30.00 & Heavy Oil & $19,488.70$ \\
\hline Generadora CS & 30.20 & Coal & $14,765.10$ \\
\hline Arizona Vapor & 12.50 & Heavy Oil & $10,275.20$ \\
\hline Genosa & 12.40 & Heavy Oil & $4,332.00$ \\
\hline Industria Textiles del Lago (ITDL3) & 30.00 & Heavy Oil & $2,487.00$ \\
\hline Tampa & 80.00 & Diesel & $2,150.00$ \\
\hline Industria Textiles del Lago (ITDL6) & 30.00 & Heavy Oil & $1,695.00$ \\
\hline Generadora Progreso & 22.00 & Heavy Oil & $1,358.20$ \\
\hline Stewart \& Stevenson & 51.00 & Diesel & 215.54 \\
\hline Escuintla Gas 5 & 41.85 & Diesel & 178.45 \\
\hline Inteccsa Bunker & 3.00 & Heavy Oil & 158.50 \\
\hline
\end{tabular}




\begin{tabular}{|l|r|l|r|}
\hline Coenesa & 10.00 & Diesel & 73.45 \\
\hline Escuintla Gas 3 & 35.00 & Diesel & 15.64 \\
\hline Inteccsa Diesel & 6.40 & Diesel & 13.60 \\
\hline Laguna Gas & 26.00 & Diesel & 0.00 \\
\hline
\end{tabular}

In this table the actual electric generations in 2011 are also indicated, and the plants are sorted with the parameter for the latter discussion. Figure 5 indicates the typical energy supply in the dry season in 2011.

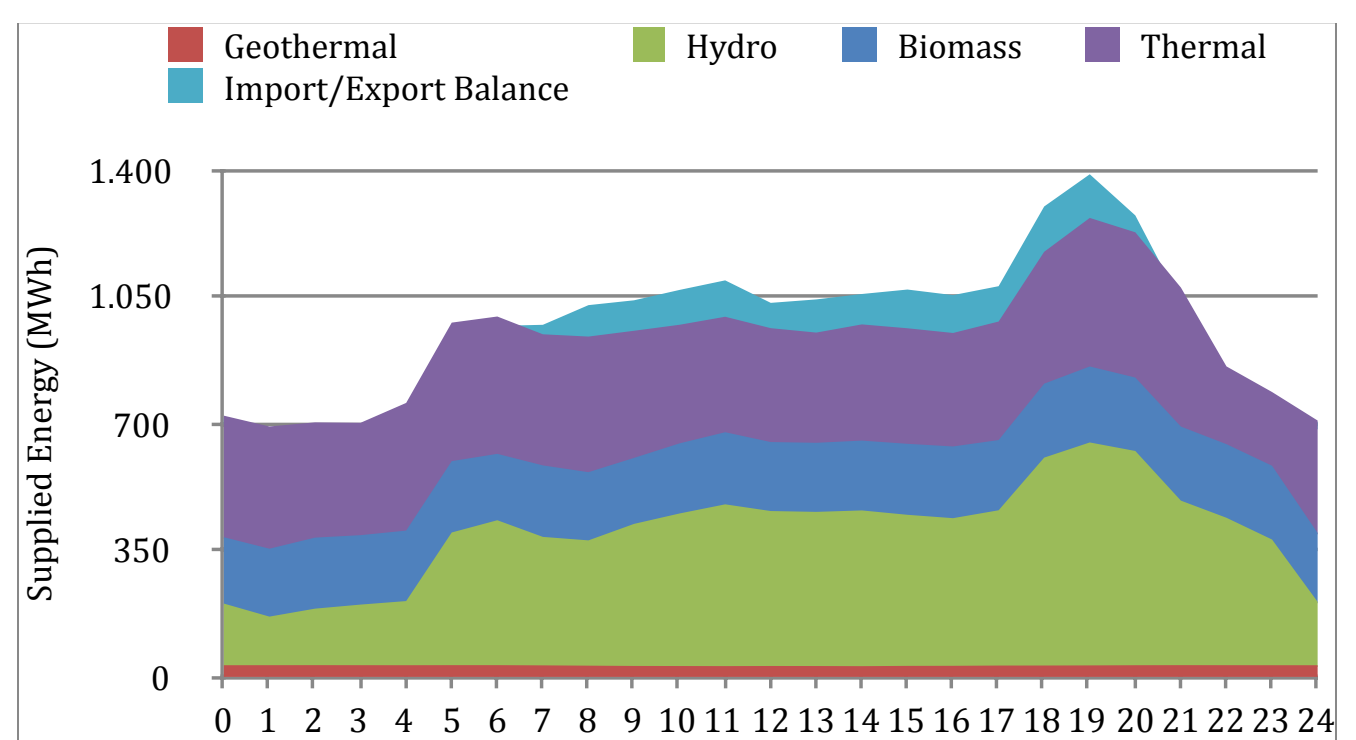

Figure 5. Guatemala's typical energy supply in dry season in 2011 (Administrador del Mercado Mayorista 2014).

In a short term, the output of the geothermal and biomass power plants is constant, and the hydro power plants are operated under a schedule planed in advance. The output of the thermal power plants is controlled to respond to the short-term fluctuation of the demand.

In December 2013, any PV systems have not been introduced into the electric power grid, as seen in Figure 2.

\subsection{Electric Power Grids}

Guatemala's electric system consists in one grid, and it connects all the power plants and all urban and most rural areas. It makes the analysis of the grid management simple, and it is the advantage of this study. A map of Guatemala's electric system is indicated in Figure 6.

This system is managed by Wholesale Market Administrator (Administrador del Mercado Mayorista, AMM) who is responsible for estimating the daily energy demand and preparing an electric generation schedule for the available power plants.

\subsection{Electricity Demand}

The typical energy demand curve for the year 2011 is indicated in Figure 7. The demand increases during the day and reaches its peak in the early evening. The demand in the midnight is about half of the peak demand.

\subsection{Electric Power Trading}

Guatemala imports or exports the electric power between the neighbor countries; Mexico and El Salvador. Figure 8 indicates the typical daily import-export trend of the trading electric power. 


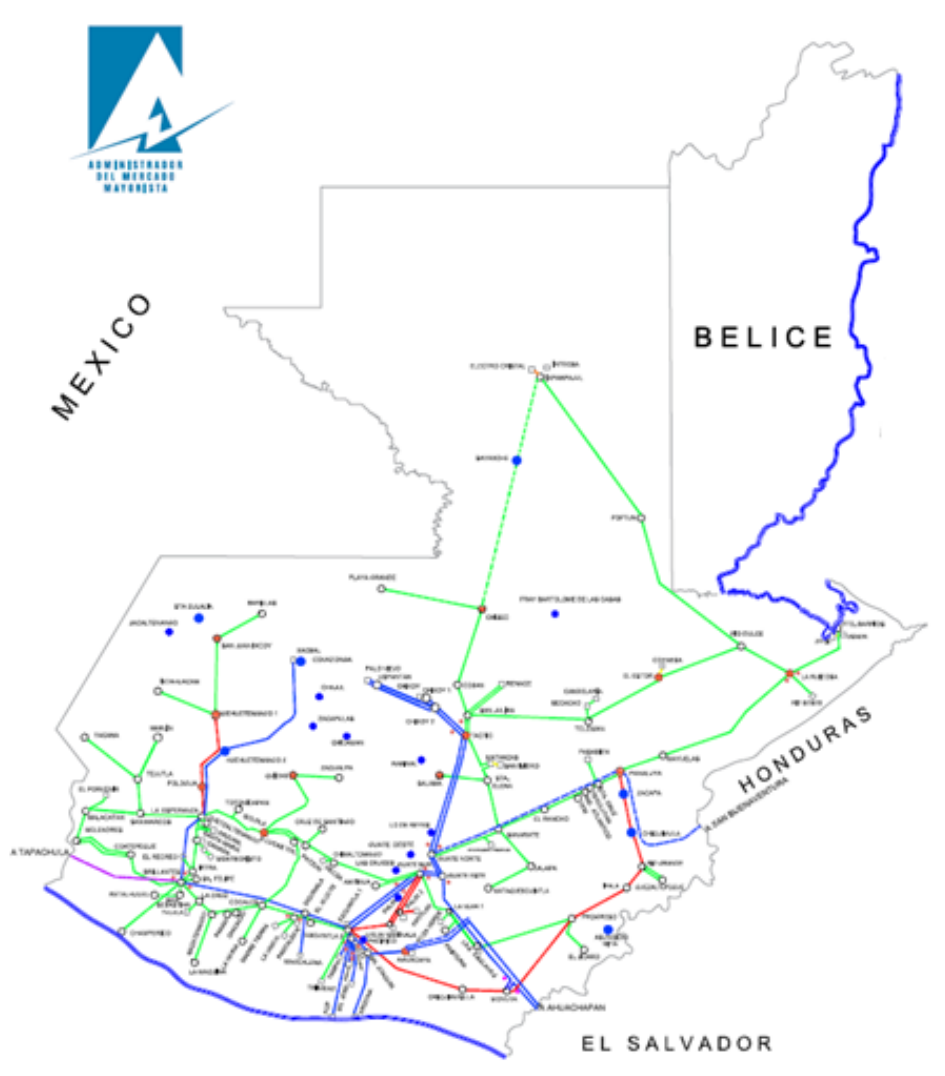

Power plant

S Sub-PowerStation

$13.8 \mathrm{kV}$ transmission line $69 \mathrm{kV}$ transmission line

$138 \mathrm{kV}$ transmission line $230 \mathrm{kV}$ transmission line

$230 \mathrm{kV}$ transmission line, double circuit $400 \mathrm{kV}$ transmission line

Future projects

- - - $230 \mathrm{kV}$ transmission line

---- $138 \mathrm{kV}$ transmission line

$----69 \mathrm{kV}$ transmission line

Sub-PowerStation

$\otimes$ Sub-PowerStation, update

Figure 6. Guatemala's electric power grid as of December 2011 (Administrador del Mercado Mayorista 2014).

Figure 7. Guatemala's typical daily energy demand curve in 2011 (Administrador del Mercado Mayorista 2014).
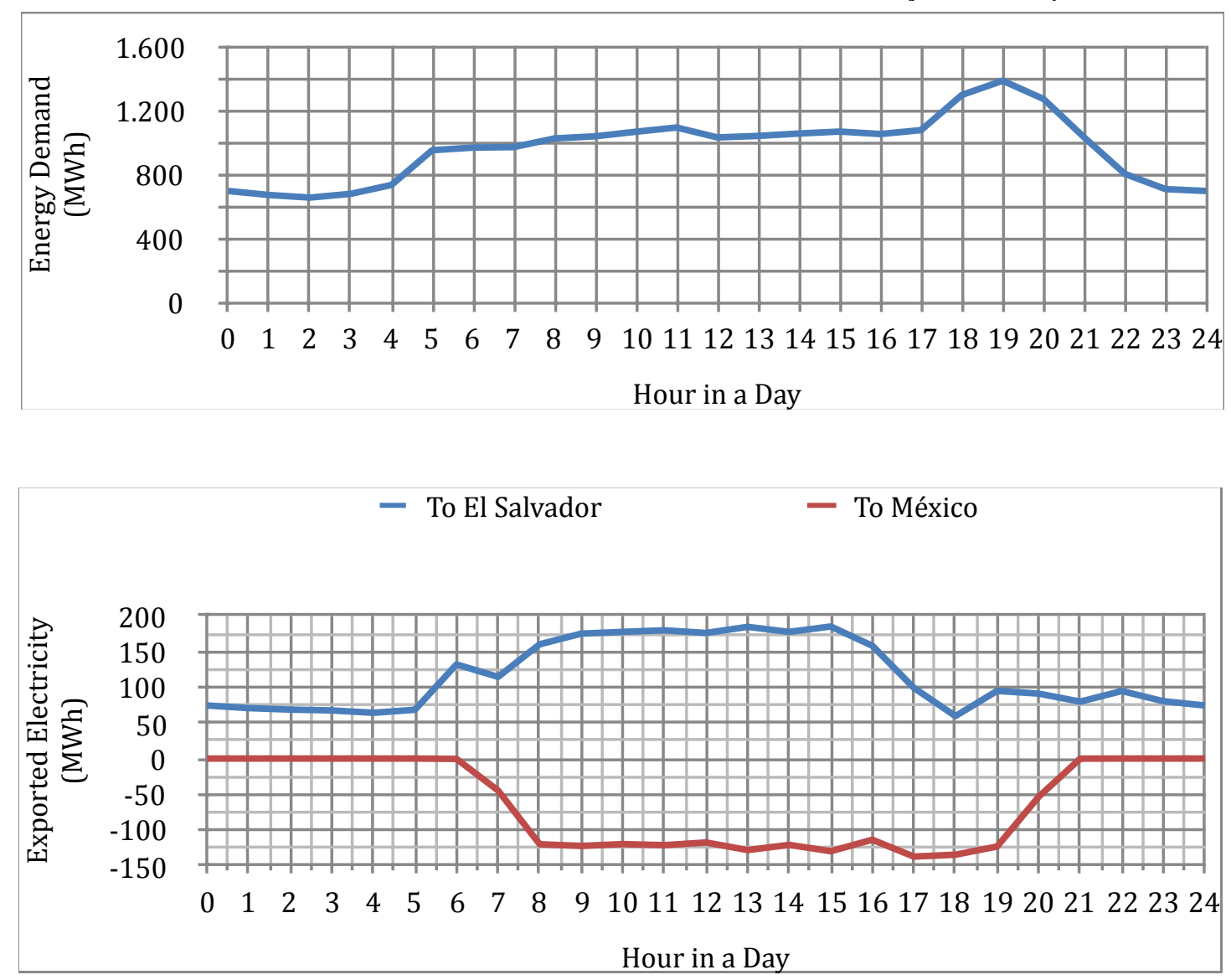

Figure 8. Typical daily exported electricity in Guatemala in 2011; negative values indicate import (Administrador del Mercado Mayorista 2014). 
The imported power supports the electricity demand usually in daytime, as shown in Fig. 5. However, most of the trading electric power, about $150 \mathrm{MWh}$ in daytime is passing through Guatemala, and the consumed power in Guatemala is about $50 \mathrm{MWh}$ during the daytime as shown in Figures 5 and 7. The consumed power is small compared with the total capacity 2,795 MW of the electric power plants in Guatemala.

\section{Grid Managing Analysis}

\subsection{Analysis Model}

In order to analyze Guatemala's electric system, we propose an analysis model based on the System Dynamics. The System Dynamics is a modeling tool to analyze the nonlinear behavior of complex systems over time. It's constituted with stocks, flows, feedback loops and time delays. It was originally developed by Forrester (Forrester, 1961) in order to provide a tool for managers to understand business and industrial processes and their interactions. However, its applications cover any complex system, i.e. social, managerial, economic, or industry processes (System Dynamics Society, 2014).

\subsection{Model Description}

\subsubsection{Model Structure}

The model proposed here includes all electric power plants and electric power grids in Guatemala. Since the model includes 85 plants, the entire structure of the model cannot be indicated in this article; therefore a simplified model is indicated in Figure 9 for the explanation of the model structure.

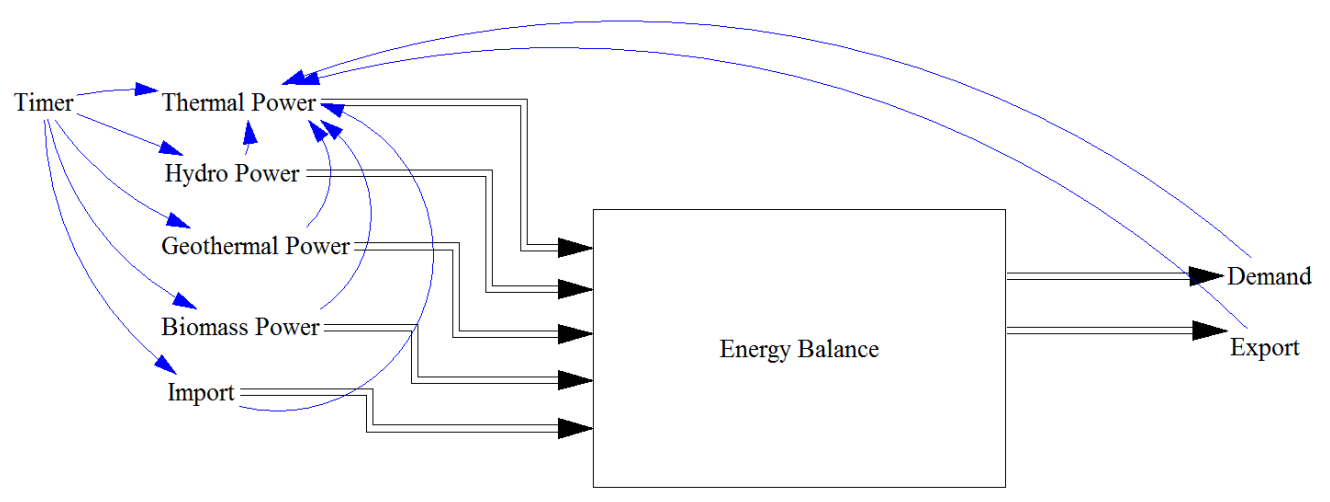

Figure 9. Schematic view of Guatemala's electric power grid model for representing current status.

The Timer in the figure generates the date and time continuously, and synchronizes all the behavior in the model. All plants, i.e. Thermal Power, Hydro Power, Geothermal Power and Biomass Power plants, generate electric power and supply it to the demand side under the direction of the Timer. The information of the Demand is feedback to the Thermal Power plants to manage them for keeping electric balance between the generations and demand. The electric power trading is also taken into the account at the nodes Import and Export in the figure. These interactions are set in as nodes and logical functions which simulate the electric system under the actual rules.

The flows of electric power and information are indicated by double and single arrows, respectively in the figure.

\subsubsection{Electric Power Plants except Thermal Power Plants}

The hydro, biomass and geothermal power plants in Guatemala are operated on the schedule planed in advance. Therefore in the model, the database for the operation schedule for each plant is prepared, and each plant generates electric power in accordance with the database under the direction of the Timer in Figure 9. The generation record in 2011 published from AMM (Administrador del Mercado Mayorista, 2014) is used to prepare the database. 


\subsubsection{Electric Power Demand}

The electric power demand changes due to social activity which is difficult to simulate directly. Therefore the database for the Demand in Figure 9 is prepared from the expected electricity demand in 2011 reported by AMM (Administrador del Mercado Mayorista, 2014) instead of the actual one.

\subsubsection{Electric Power Trading}

The import/export electric power between neighbor countries is simulated with the database which is prepared from AMM (Administrador del Mercado Mayorista, 2014) in the model, similar to the electric power demand.

\subsubsection{Thermal Power Plants}

Guatemala's law forces the electric power grid administrator, AMM, to use renewable energy sources before using the non-renewable ones, and the thermal power plants will be used only to supply deficit of the electric power to the demand. It means that the thermal power plants are operated to achieve a balance between the electric power supply and the demand. The Thermal Powers are monitoring the generation of all other plants and the electric trade and the feedback from the Demand, and are controlled by the power generation in the model as shown in Fig. 9. Since there are several types of thermal power plants with different fuel types, each plant has its own priority to operate in accordance to the following items:

- Energy Prices; is directly linked to electricity prices. The cheaper the fuel the more priority it gets. Coal is the cheapest, and heavy oil and diesel follow it in order.

- Efficiency; is directly linked to electricity prices too. The more efficient a power plant is the better priority it has.

- Reaction time; means how long it takes for the power plant to warm up and start generating.

A plant with higher priority works more than the one with lower priority. In the model, the thermal power plants communicate among them, and work following to the priority for keeping the electric power balance between the generation and the demand.

The priority of each power plant is set by AMM using the three items listed above, their interaction and contributions to the system are simulated with nodes and logical functions in this model.

\subsubsection{Model Validation}

In order to evaluate the validity of the developed model, the model is performed under the conditions in the year 2011 and the simulated thermal power generations are compared with the actual ones. The coefficient of determination between the simulated generation and the actual one of 11 thermal plants are listed in Table 3.

Table 3. Accuracy of the thermal power plants operation in 2011 represented with a model constructed with System Dynamics.

\begin{tabular}{|l|r|r|l|r|}
\hline Thermal Power Plant & $\begin{array}{l}\text { Actual } \\
\text { Generation } \\
\text { in 2011 } \\
\text { (MWh/year) }\end{array}$ & $\begin{array}{l}\text { Simulated } \\
\text { Generation } \\
\text { (MWh/year) }\end{array}$ & $\begin{array}{l}\text { Difference } \\
\text { in \% }\end{array}$ & $\begin{array}{l}\text { Coefficient of } \\
\text { determination between } \\
\text { simulated and actual } \\
\text { power generations }\left(\mathbf{R}^{2}\right)\end{array}$ \\
\hline Arizona Vapor & $10,275.20$ & $9,526.43$ & $(-) 7.29 \%$ & 0.95 \\
\hline Las Palmas 2 & $437,521.09$ & $440,070.00$ & $(+) 0.58 \%$ & 0.96 \\
\hline San José & $822,155.12$ & $845,645.00$ & $(+) 2.86 \%$ & 0.96 \\
\hline La Libertad & $100,874.54$ & $99,710.00$ & $(-) 1.15 \%$ & 0.78 \\
\hline
\end{tabular}




\begin{tabular}{|l|r|r|l|r|}
\hline Poliwatt & $558,486.51$ & $598,539.00$ & $(+) 7.17 \%$ & 0.69 \\
\hline Arizona Bunker & $621,056.48$ & $629,156.00$ & $(+) 1.30 \%$ & 0.81 \\
\hline Puerto Quetzal Power & $94,380.43$ & $118,298.00$ & $(+) 25.34 \%$ & 0.73 \\
\hline Las Palmas Bunker & $91,428.93$ & $102,071.00$ & $(+) 11.64 \%$ & 0.74 \\
\hline Industrias Textiles del Lago U10 & $19,488.70$ & $21,233.00$ & $(+) 8.95 \%$ & 0.81 \\
\hline Genor & $203,001.98$ & $154,684.00$ & $(-) 23.80 \%$ & 0.65 \\
\hline Electro generación Bunker & $21,287.98$ & $25,354.00$ & $(+) 19.10 \%$ & 0.60 \\
\hline Total & $\mathbf{3 , 0 4 4 , 2 8 6 . 4 3}$ & $2,979,956.94$ & $(+) 2.16 \%$ & $\mathbf{0 . 9 2}$ \\
\hline
\end{tabular}

The coefficient is defined as follows:

$$
R^{2}=1-\left(S S_{r e s} / S S_{t o t}\right)
$$

Where $S S_{\text {res }}$ is the sum of squares of residuals and $S S_{\text {tot }}$ is the total sum of squares and they are defined as:

$$
\begin{aligned}
& S S_{\text {res }}=\sum i\left(y_{i}-f_{i}\right)^{2} \\
& S S_{\text {tot }}=\sum i\left(y_{i}-\bar{y}_{i}\right)^{2}
\end{aligned}
$$

Where $y_{i}$ is the actual power generation data in $2011, f_{i}$ is the simulated power generation and $\bar{y}$ is the mean of the actual generation. The other thermal plants work less than 100 hours (about $1 \%$ of a year) in a year, and the data isn't effective for this validation. The coefficient $R^{2}$ for all simulated thermal power operation is 0.92 . These results show the validity of the model.

\section{Impact Analysis of PV Installation}

\subsection{Model Reconstruction with PV System}

A large-scale PV system is installed with the optimized conditions in the model constructed with the System Dynamics for the impact analysis of PV installation to the grid. The install conditions, e.g. location and tilted panel angle, and time series meteorological data are estimated in Part 1 (Wyss Porras et al., 2015).

The model including the PV system is indicated in Figure 10. The model in this figure is simplified for the explanation. It is found that the PV System is added similar to the ordinal electric power plants by the comparison between Figures 9 and 10.

In this model, Power Rating of the PV System is fixed first. The meteorological database is constructed from the result computed with the meteorological model (Wyss Porras et al., 2015) at Section 3 in Part 1. Irradiance and Temperature of the Meteorological Model in Figure 10 are generated from the meteorological database under the direction of Timer. The PV System evaluates its output from the database with the method explained at Section 4 in Part 1, and supply the output to the electric power grid together with the ordinal power plants. 


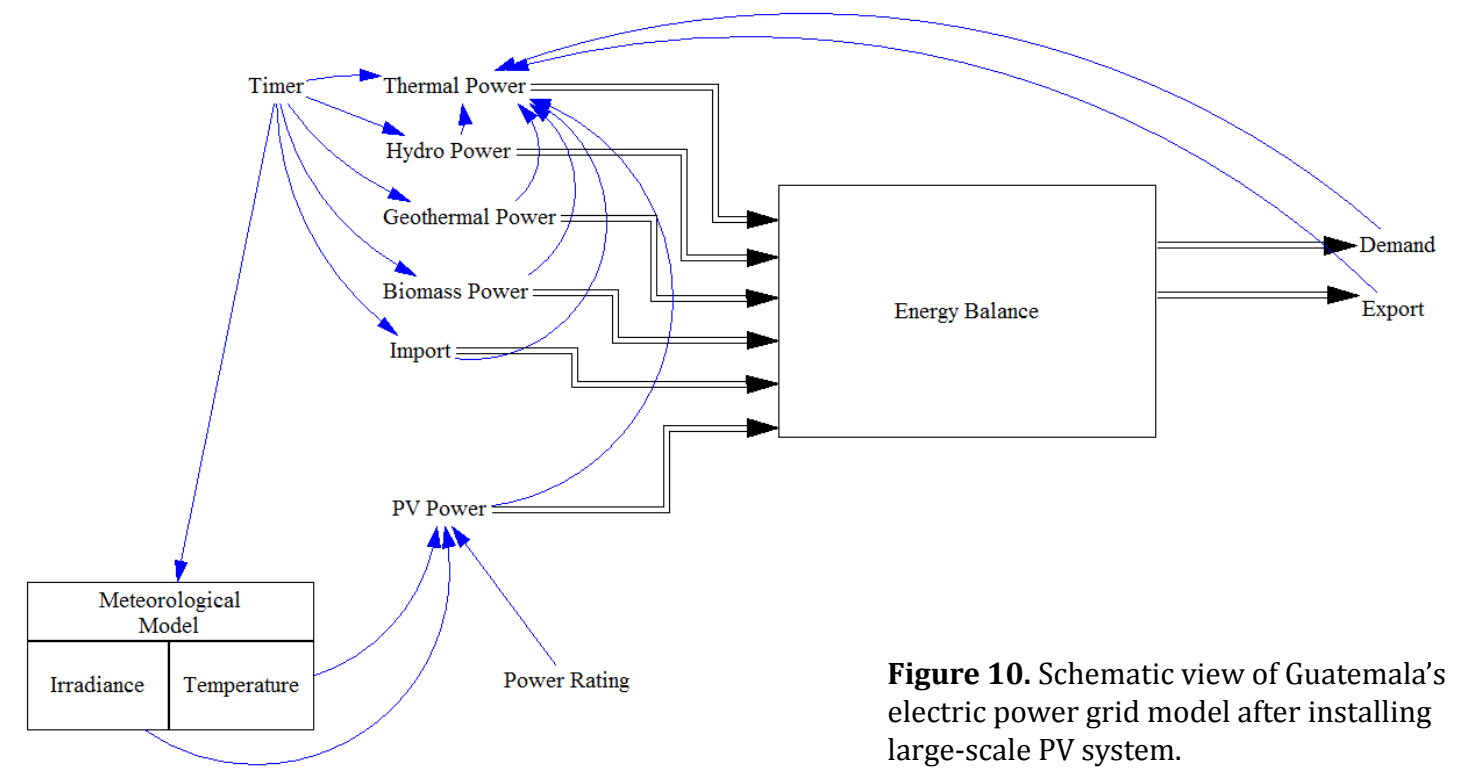

\subsection{Results and Discussions}

By installing the PV system, the electric generation of the thermal power plants may be reduced, because the plants get feedback from the demand and control the electric balance on the grid as shown in Figure 10. The reduction of the power plants' generation is evaluated as the impact of the PV installation to the electric power grid. The capacity of the installed PV system, which corresponds to the Power Rating in Figure 10, changes from 0 to $200 \mathrm{MW}$ in this impact analysis. The period of the simulation is the complete year 2011. The generation of each thermal power plant is estimated with different install capacity of the PV system as shown in Figures 11 to 14.

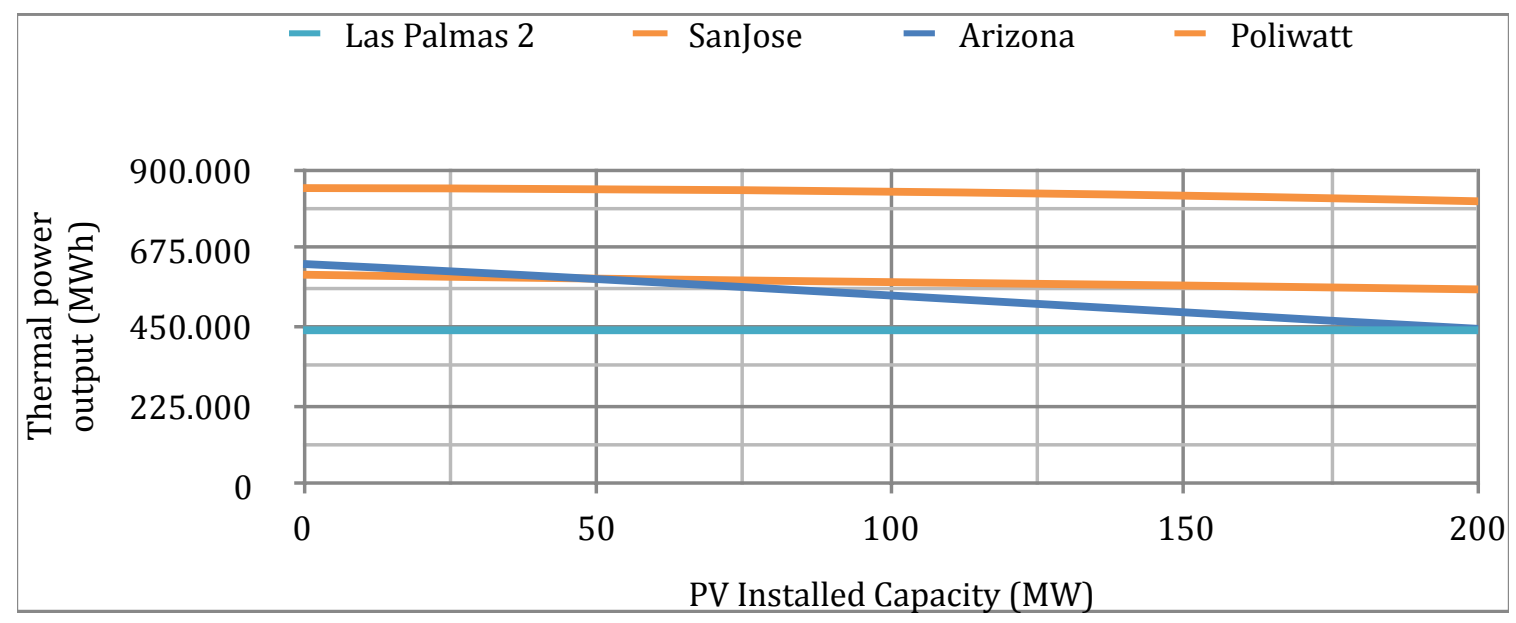

Figure 11. Simulated yearly output of largest generation thermal power plants after installing large-scale PV system.

The plants are categorized in these figures with their actual generation scale. Each thermal power plant is operated with the own priority defined by AMM from the energy cost, efficiency and the reaction time. And the PV installation impact is discussed with the actual power generation simulated on the model. The capacity and the actual generation of each thermal power plant is listed and sorted with the generation in Table 2. The generation of some power plants, i.e. Tampa, Stewart \& Stevenson and Escuintla Gas 5 is small compared with their capacities, as seen in the table, because of their low priority.

In Figure 11, the largest generation power plants are grouped. They are operated throughout the year in order to balance the demand with the energy generation after the use of the renewable energy sources. In this figure, the Arizona power plant's generation is most evidently reduced by $29 \%$ from 629,156 MWh before installing the PV system to 444,121 MWh with the 200 MW PV system installation. The Arizona power plant generates with internal combustion engines and heavy oil, and the plant can control the generation easily; but, the energy cost is expensive. Under this condition, the Arizona plant has the 


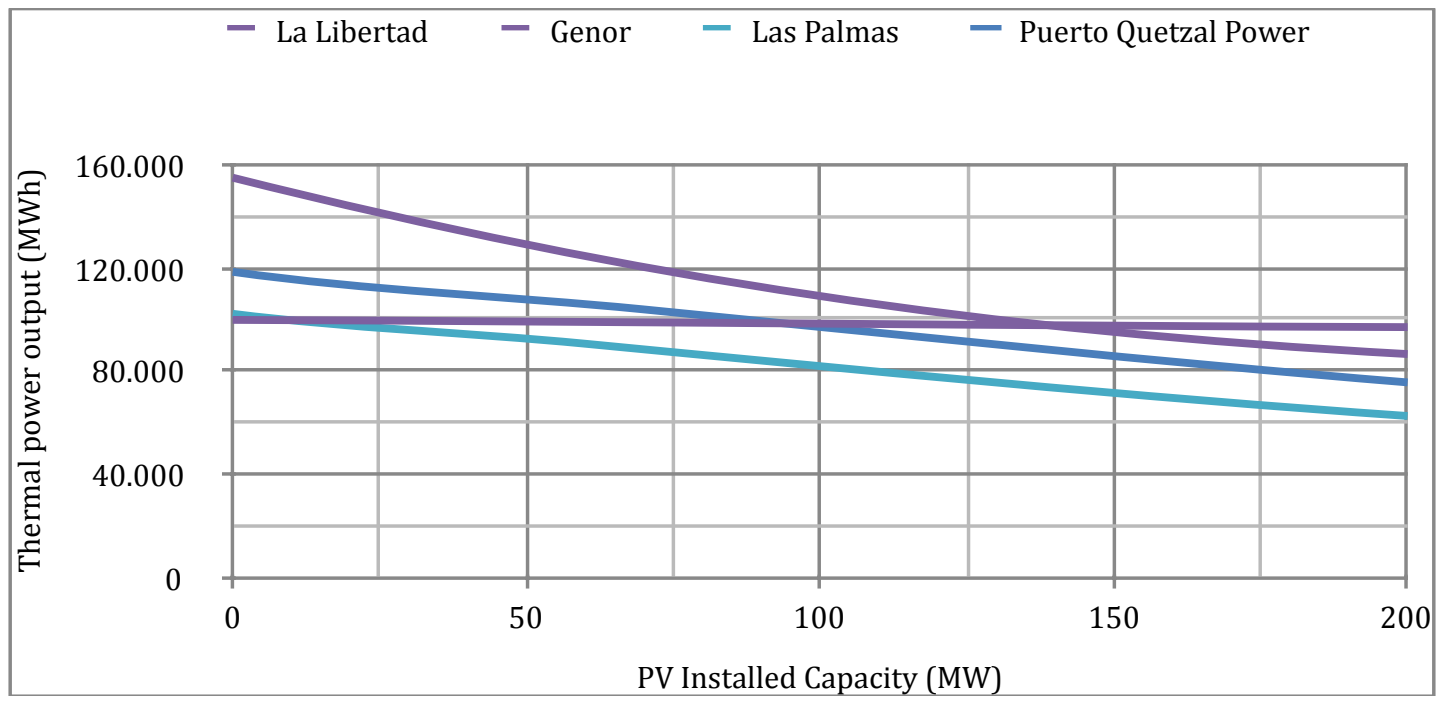

Figure 12. Simulated yearly output of middle-large generation thermal power plants after installing large-scale PV system.

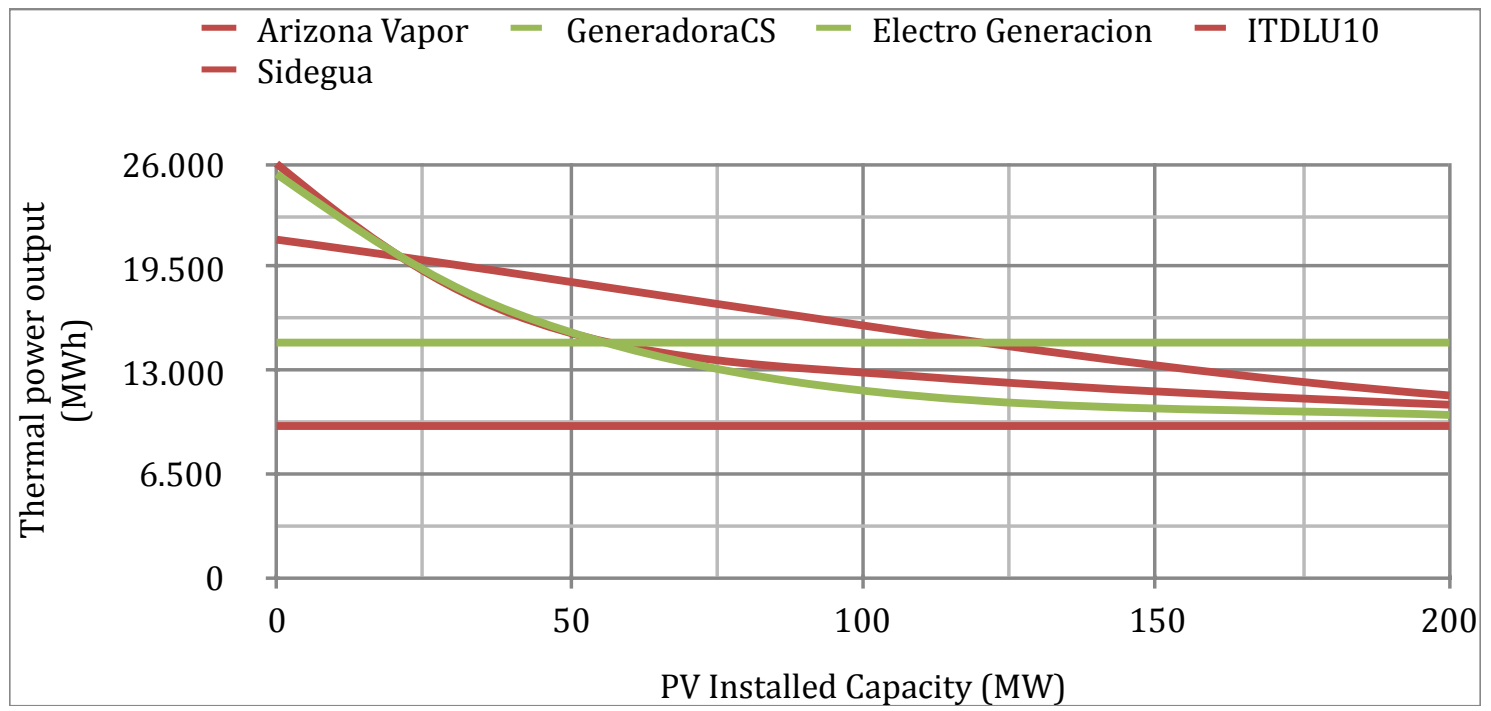

Figure 13. Simulated yearly output of middle-small generation thermal power plants after installing large-scale PV system.

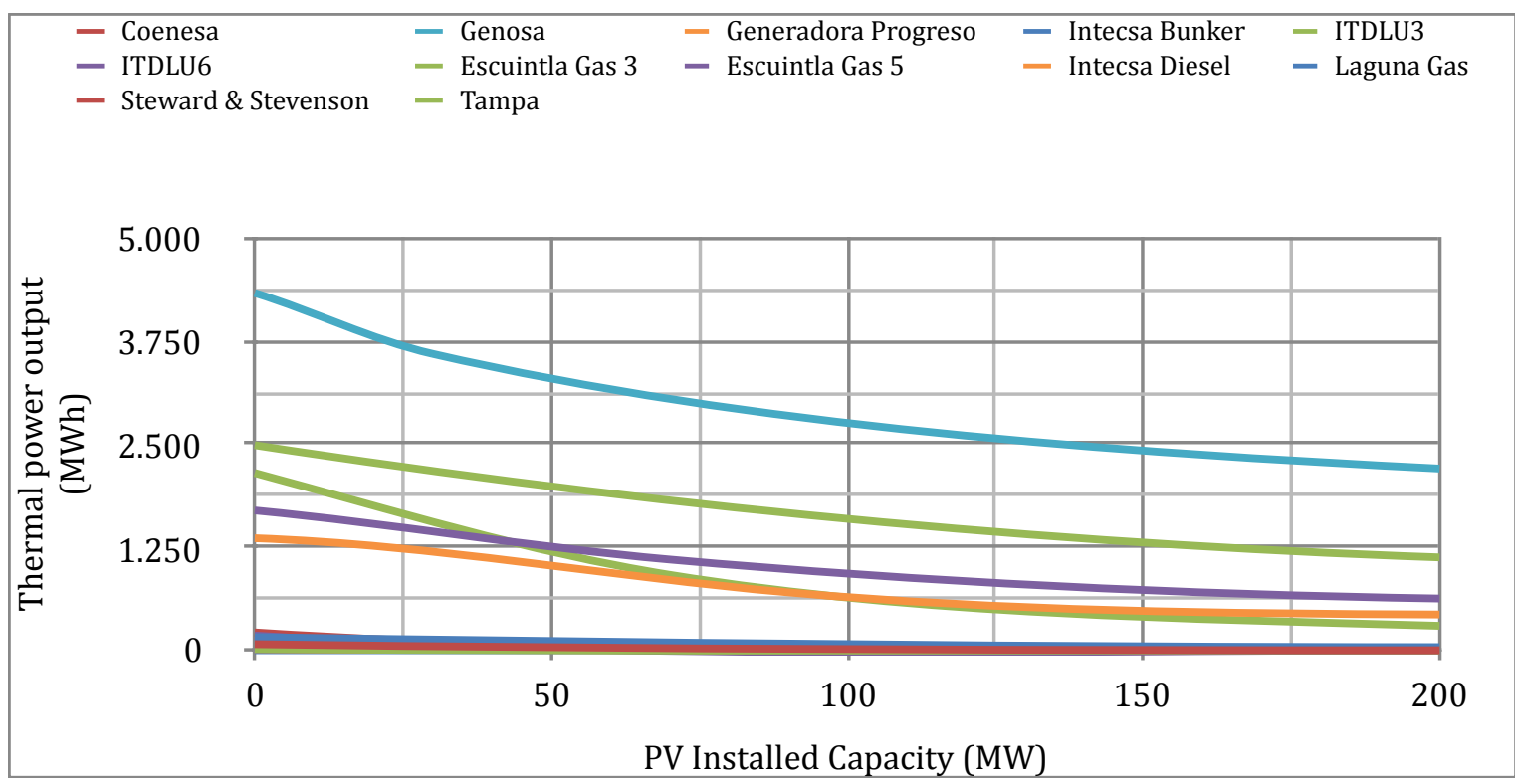

Figure 14. Simulated yearly output of small generation thermal power plants after installing large-scale PV system. 
lowest priority in operation among the largest generation power plants, and it may reduce evidently the operation when the PV installed as the result of the simulation.

On the other hand, the Las Palmas 2 power plant generates 440,070 MWh, and it doesn't get any impact from the installation of the PV system. This plant uses coal as fuel and it is the latest plant which was installed in May 2010; besides, it has the highest priority among the four largest generation power plants.

We define the parameter 'sensitivity' to the impact of the PV installation as the negative gradient of graph in Figure 11. It's evaluated the reduction of the generation in unit MWh divided by the increase of PV installed capacity in unit MW. The sensitivity of Arizona power plant is $957.19 \mathrm{MWh} /$ MW at the 0 MW PV system installation, and the largest sensitivity among the plants in Figure 11. On the other hand, the sensitivity of the Las Palmas 2 power plant is $0 \mathrm{MWh}$ /MW on the same situation.

The impact of the PV system installation to the mid-large generation power plants is presented in Figure 12. The plants in this class are for supporting the increasing demand in daytime and the early evening shown in Figure 7, especially in the dry season when hydropower plants cannot generate enough power. They usually have lower priority in operation than the largest generation power plants in Figure 11. Their generations reduce as the install capacity of the PV system increases. Only La Libertad has a very small reaction to the installation of the PV system; the sensitivity is only $9.04 \mathrm{MWh} /$ MW at the 0 MW PV system installation, and it is negligible. There are several reasons for their lower priority compared with those in the largest generation power plants. First, their efficiency is lower than the largest generation power plants due to the scale merit of the generation. Second, they were all installed between 1993 and 1998, and use heavy oil as fuel and their operating prices are higher than those in Figure 11. Their sensitivities at the $0 \mathrm{MW}$ PV installation are from 214 to $340 \mathrm{MWh} /$ MW, except the La Libertad power plant.

The impact of the PV system installation to the mid-small generation power plants is presented in Figure 13. Their operating cost is higher, and therefore their priority is lower than the larger plants in Figure 12. These power plants change their output throughout the day due to changing the demand, and mainly support the peak demand in the early evening in Figure 7. The usual operation period of the plants is after the sunset, and some plants, e.g. Arizona and Generadora CS, don't get strongly affected from the PV installation, and their sensitivities aren't large.

Figure 14 shows the impact of the PV system installation on the smallest generation thermal power plants. The amount of the electric generation is small, but they are required, because they support the peek and emergent demands for the grid managing. These power plants are the most expensive ones, using diesel or heavy oil as fuel.

The relation between the install capacity of the thermal power plants and their sensitivity to the PV installation is plotted in Figure 15.

One of the largest generation plants, Arizona has the highest sensitivity as shown in this figure, because of its low cost operation and short reaction time, as explained before. In this figure, the sensitivities of the middle-large generation power plants tend to be larger than the others. The plants of this class works mainly in the daytime and early in the evening to support the high demand. Therefore, the installed PV system supply electric power in the daytime instead of the thermal plants, and the plants may reduce their operation. On the other hand, the large thermal plants, except Arizona, operate throughout the year as the base load power plants, and their sensitivity to the PV installation is similar as shown in Figure 15.

Most power plants which reduce the generation due to the installed capacity of the PV system increase. And also their sensitivity decreases; for example, the sensitivity of the middle-large plant Genor in Figure 12 decreases from 339 with 0 MW PV installation to 185 with 200 MW PV installation. This may be caused by the limitation of the ability of the electric power grid to the acceptance of the fluctuation of PV generation which occurs due to changes of weather and the sun altitude. The fluctuation becomes larger as the install capacity of the PV system becomes larger. When the fluctuation becomes larger, the electric power grid has to keep preliminary plants mainly for the absorption of the fluctuation. 
Large class $\quad$ Middle-Large class $\triangle$ Middle-Small class $\times$ Small class

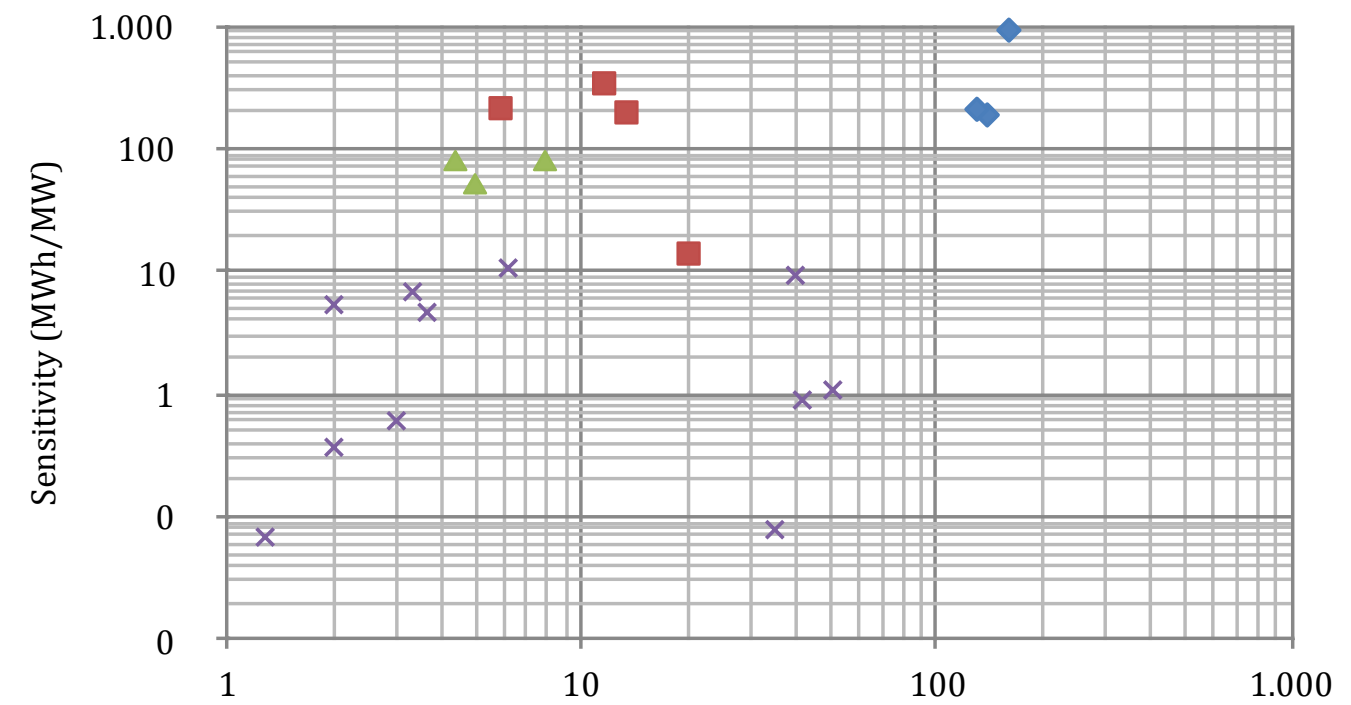

Thermal Power Plant Capacity (MW)

Figure 15. Sensitivity of thermal power plants compared with their generation.

\section{Conclusions}

The impact of the installation of a photovoltaic system to the electric power grid in Guatemala is simulated with the nonlinear analytical tool, called 'System Dynamics'. The installing condition of the PV system is the estimated in Part 1 (Wyss Porras et al., 2015), in which estimation, this installing condition is optimized in efficiency under the weather and the irradiance in Guatemala.

In this simulation, all 85 power plants operated in 2011 are represented and it is evaluated the reduction of the electric generation of the individual thermal power plant due to the installation of the PV system. The contribution of the PV installation to the reduction of the thermal power plants' operation is very small or null for the largest generation thermal plants because of their high efficiency and low cost in operation. On the other hand, the middle-large generation thermal power plants reduce their operation after installing PV system in this simulation, because these power plants work mainly in daytime to support the high demand, and the installed PV system will supply the electric power in daytime instead of the plants after the PV installation. The reduction of thermal power plants' operation becomes large as the PV installing capacity becomes large, but its reduction gradient becomes small as the PV installing capacity increases. This may cause the capacity limitation to allow the time variation of the PV power generation.

\section{References}

Administrador del Mercado Mayorista. (2014). "Administrador del Mercado Mayorista, Guatemala C.A.". Administrador del Mercado Mayorista. Retrieved December 2014 < http://www.amm.org.gt/>.

Ahmad, Salman, Razman Mat Tahar, Firdaus Muhammad-Sukki, Abu B. Munir, and Ruzairi Abdul Rahim. (2015). "Role of feed-in tariff policy in promoting solar photovoltaic investments in Malaysia: A system dynamics approach." Energy DOI.

Forrester, Jay W. (1961). Industrial Dynamics. Cambridge: The MIT Press.

Hsu, Chiung-Wen. (2012). "Using a system dynamics model to assess the effects of capital subsidies and feed-in tariffs on solar PV installations". Applied Energy 205-217. 
Instituto Geográfico Nacional, Guatemala C.A. 2014. "Instituto Geográfico Nacional, Guatemala C.A." Retrieved October $2014<$ http://www.ign.gob.gt/>.

IRENA, International Renewable Energy Agency. 2012. "Renewable Energy Technologies' Cost Analysis Series". Industry Report, Solar Photovoltaics, IRENA International Renewable Energy Agency, Madar, Abu Dhabi, United Arab Emirates.

Jäger-Waldau, Arnulf. (2012). "PV status report 2012." Joint Research Centre, Institute for Energy and Transport, European Commisision, Luxembourg. Retrieved July 14, $2014<$ https://ec.europa.eu/jrc/>, $<$ http://re.jrc.ec.europa.eu/refsys/pdf/PV\%20reports/PVReport-2012-Part1.pdf $>$.

Kaifel, Anton. (2011). "P2IONEER - Virtual and Hybrid Power Plant Simulation”. Retrieved June 12, 2015 $<$ http://www.zsw-bw.de/themen/energiewirtschaft/p2ioneer.html>.

Li, Chen, Lisha Zhou, Na Li, and Ming Zeng. (2012). "Modelling and simulation of Power Grid Engineering Project baed on System Dynamics on the Background of Smart Grid". Systems Engineering Procedia 92-99.

Movilla, Santiago, Luis J. Miguel, and L. F. Blázquez. (2013). “A systems dynamics approach for the photovoltaic energy market in Spain". Energy Policy 142-154.

Ramli, Makbul A. M., Ayong Hiendro, Khaled Sedraoui, and Ssennoga Twaha. (2015). "Optimal sizing of grid-connected photovoltaic energy system in Sauid Arabia". Renewable Energy 75:489-495.

Silveira, Jose L., Celso E. Tuna, and Wndell d. Q. Lamas. 2013. "The need of subsidy for the implemantation of photovoltaic solar energy as supporting of decentralized electrical power generation in Brazil." Renewable and Sustainable Energy Reviews 20:133-141.

System Dynamics Society. (2014). "System Dynamics Society." Retrieved December $2014<\underline{\text { http: } / /}$ www.systemdynamics.org>.

Wyss Porras, Juan E., Susumo Shimada, Jun Yoshino, and Tomonao Kobayashi. (2015). “Evaluation of the Impact of Photovoltaic Power Plants in to Guatemala's Electric Grid, Part 1". Labor \& Engenho 9(4): 90-102. Campinas [SP] Brazil. <http://periodicos.bc.unicamp.br/ojs/index.php/labore/article/view/8641639>. 